Review

\title{
Enhanced Accumulation of Vitamins, Nutraceuticals and Minerals in Lettuces Associated with Arbuscular Mycorrhizal Fungi (AMF): A Question of Interest for Both Vegetables and Humans
}

\author{
Marouane Baslam ${ }^{1}$, Idoia Garmendia ${ }^{2}$ and Nieves Goicoechea ${ }^{1, *}$ \\ 1 Department of Environmental Biology, School of Sciences, University of Navarra, Irunlarrea, 1, \\ 31008- Pamplona, Spain; E-Mail: bmarouane@alumni.unav.es \\ 2 Environment and Earth Sciences Department, University of Alicante, P.O. Box 99, E-03030 \\ Alicante, Spain; E-Mail: idoia.garmendia@ua.es \\ * Author to whom correspondence should be addressed; E-Mail: niegoi@unav.es; \\ Tel.: +34-948-425-600 (ext. 806489); Fax: +34-948-425-619.
}

Received: 3 December 2012; in revised form: 8 February 2013 / Accepted: 1 March 2013 /

Published: 20 March 2013

\begin{abstract}
Lettuce (Lactuca sativa L.) is extensively grown and is the most widely used food crop for the called "Fourth Range" of vegetables. Lettuce exhibits healthy properties mainly due to the presence of antioxidant compounds (vitamins $\mathrm{C}$ and $\mathrm{E}$, carotenoids, polyphenols) alongside significant fibre content and useful amounts of certain minerals. Lettuce can establish a mutualistic association with arbuscular mycorrhizal fungi (AMF). The establishment of the symbiosis involves a continuous cellular and molecular dialogue between both symbionts, which includes the activation of antioxidant, phenylpropanoid or carotenoid metabolic pathways. The presence of AMF colonizing roots of greenhouse-grown lettuces can induce an accumulation of secondary metabolites, vitamins and minerals in leaves that overcome the dilution effect due to the increased size of mycorrhizal plants. Therefore, AMF would allow the intake of minerals and compounds with antioxidant properties to be enhanced without increasing the consumption of lettuce in the diet. In addition, increased quantities of secondary metabolites may help lettuce plants to withstand biotic and abiotic stresses. Our review discusses the influence exerted by several environmental factors and agronomic practices on the ability of AMF for enhancing the levels of vitamins, nutraceuticals and minerals in leaves of green and red-leaf types of lettuces.
\end{abstract}


Keywords: arbuscular mycorrhizal fungi; ascorbate; carbon dioxide; carotenoids; drought; Lactuca sativa; minerals; phenolics; seasonality; tocopherol

\section{Introduction}

Since plants are devoid of motility and an immune system, they have developed alternative defense strategies that include a huge variety of secondary metabolites (SMs) as tools to overcome stress constraints, adapt to the changing environment and survive. These SMs also play a major role in helping plants to defend themselves against herbivores (insects, mollusks and vertebrates), microbes, viruses and other competing plants [1]. While the biosynthesis of several SMs, such as carotenoids or lignin, may be mainly constitutive, the synthesis of numerous SMs, such as many phenolic compounds, can be induced and enhanced by both abiotic and biotic stresses. It is well known that the accumulation of SMs may increase when plants are undergoing high or low temperatures, high light intensity, UV radiation, drought, mineral deficiencies, salinity or pathogen infection [2]. The enhanced amount of biologically active SMs can be a consequence of either the activation of genes responsible for their synthesis, transport and storage or the hydrolysis of glycosides that are stored as "prodrugs" in plant cells. However, the production of these compounds (whose levels in tissues constitute less than $1 \%$ of the total dry weight) greatly depends on the physiological and developmental stage of the plant $[1,2]$.

There is increasing evidence that several plant SMs can exert protective functions in the human body, and thus they are starting to be recognized as important integrants of a nutritious diet that promotes long-term health. In fact, some plant SMs can act as antioxidants by quenching free radicals thus reducing the risk of health problems related to the production of free-radicals, such as cancer and atherosclerosis [3]. The antioxidant effectiveness of carotenoids increases with the number of conjugated double bonds. Among carotenoids, lutein and lycopene may potentially prevent some types of cancer; $\beta$-carotene and lycopene have been shown to be inversely related to the risk of cardiovascular diseases and lutein and zeaxanthin can prevent disorders related to the eye, such as macular degeneration [4,5]. Phenolic compounds also have antioxidant properties; for example, anthocyanins have exhibited anti-carcinogenic effects in several cell culture systems including colon cancer cells, endothelial, liver and leukemic cells [6]. Therefore, the increasing interest in elucidating the mechanisms involved in the antioxidant activity of different compounds present in foods and beverages is justified.

Lettuce (Lactuca sativa L.), one of the most widely consumed vegetables in the human diet, can provide an important source of water, antioxidant compounds (including vitamins $\mathrm{A}, \mathrm{C}$ and $\mathrm{E}$, polyphenols and carotenoids) as well as fiber and useful amounts of certain minerals, such as $\mathrm{Ca}, \mathrm{Fe}$ and K [7-9]. Lettuce, widely grown worldwide and especially in temperate and subtropical regions, is a major food crop within the European Union. According to FAOSTAT (FAO statistics Division) 2012, the world production of lettuce and chicory in 2011 reached 24,239,979 tons on about 1 million ha. The USDA (United States Department of Agriculture) Vegetables 2011 Summary (January 2012) estimates that the total production of lettuce in USA reached 3,889,120 tons in 2011. In addition, 
lettuce is the most widely used food crop for the called "Fourth Range" of vegetables. The term originally meant fresh, cleaned, possibly chopped and mixed vegetables ready to be seasoned and eaten [10]. These vegetables are increasingly accepted by consumers because they are healthy and easy to prepare for eating.

The nutritional value of lettuce can vary greatly among different varieties or cultivars within a given species. Mou [11] found a wide range of genetic variability in the concentrations of carotenoids produced by different types (commercialized or wild) of lettuce, suggesting that it may be possible to achieve increased nutritional quality through crosses between different lettuces, at least one of them producing high levels of carotenoids. By using plant breeding and biotechnology approaches, it is also possible to develop genotypes with improved flavor and nutritional quality that can encourage consumers to eat more fruits and vegetables [12]. For example, plant breeders have been successful in obtaining a four- to seven-fold increase in vitamin C content in lettuce cv. Black Seeded Simpson, Grand Rapids and Prizehead after constitutive expression of the rat cDNA encoding L-gulono-1,4-lactone oxidase, the enzyme involved in the final step of the animal vitamin $\mathrm{C}$ biosynthesis [13]. Subsequently, Yabuta [14] reported that levels of tocopherol and activity of vitamin E increased in transplastomic lettuce plants compared with the wild-type and hypothesized that chloroplast genetic engineering can be useful for improving vitamin $\mathrm{E}$ content in lettuce. Goto et al. [15] produced transgenic lettuce with increased quantity of the iron storage protein ferritin via the integration and further expression of the ferritin gene in lettuce leaves. Despite these successful examples of genetically modified lettuces, the final commercialization of transgenic lettuce may depend not only on progress in transgene expression but also on public acceptance, economic and marketing challenges, intellectual property issues and risk assessment [11]. All these difficulties represent inducements to find alternatives to genetic engineering for improving the nutritional quality of lettuce. One of these alternatives could be arbuscular mycorrhizal (AM) symbiosis, which is the default situation for most crop plants in the field. The association of crop plants with arbuscular mycorrhizal fungi (AMF) may provide benefits to plants that include enhanced yield or improved $\mathrm{P}$ uptake and others unrelated to yield or $\mathrm{P}$ fertilizer use, such as tolerance to disease and drought, improved soil structure and $\mathrm{C}$ sequestration in soil [16]. Moreover, several studies have demonstrated the beneficial role of AMF in the increased production of health-related biomolecules by fruits or vegetables associated with them [17]. The establishment of AM symbiosis requires a high degree of coordination between the two partners based on a finely regulated molecular dialogue [18]. This communication begins in the rhizosphere with the production and exudation of signaling molecules by the host plants that are recognized by AMF and stimulate hyphal growth. Among these signal molecules strigolactones are supposed to be essential at early stages of the AM interaction [19] and recently they have been classified as a new class of plant hormones regulating above- and below-ground plant architecture, and reproductive development [20]. In lettuce, the production of strigolactones increases when plants are grown in saline soil as the establishment of AM symbiosis may be promoted in order to cope with salt stress [20]. Apart from the role of strigolactones at the early stages of symbiosis, other classes of apocarotenoids accumulate in large amounts in mycorrhizal roots at the later stages of AM association [19]. However, the molecular dialogue between mycorrhizal fungi and their host plants not only induces metabolic changes in plant roots, but also can induce the 
activation of the antioxidant metabolism [21] and the accumulation of essential oils, carotenoids, total phenolics or anthocyanins in shoots, leaves or fruits [17].

In a very recent review, Vosátka et al. [22] discuss the current achievements and bottlenecks in the development of arbuscular mycorrhizal biotechnology and industry. According to these authors, advances in the scientific knowledge of AM symbiosis have increased the potential for implementation of mycorrhizal biotechnology in horticulture and agriculture. Moreover, new technologies (such as novel formulations for liquid applications or seed coating, compounds that stimulate the formation of mycorrhizal symbiosis or new application modes) have been developed for using AMF in greenhouses or in the field. However, the weak aspects of mycorrhizal biotechnology are still the lack of appropriate, cheap, highly reproducible and effective methods for inocula purity testing and quality control [22]. Quality control in terms of infectivity, absence of pathogens and growth promoting effects in relation to dosage is essential but effective guidelines for the expanding industry have not still been adopted [16]. Currently, relatively high production costs limit the application of mycorrhizal inocula mainly to nursery-scale inoculation before transplanting or to field-scale inoculation only of high-value crops [16]. Moreover, some agricultural practices, such as plowing of soil together with high fertilizer applications, disrupt mycelial networks, limit the range of AMF that can survive in agricultural soils and inhibit or reduce the colonization of high-value crop plants, especially cereals [23].

However, and despite all the aforementioned limitations, renowned scientists highlight the key role that AM symbioses can provide to horticulture and agriculture. In the words of Smith and Smith [16] there is "imperative for research that is aimed at increasing benefits of AM symbioses in the field at a time of increasing prices of P-fertilizer and increasing demands on agriculture to feed the world". Fitter et al. [23] suggest that "it would be possible to breed crop plants with reduced root systems, because the bulk of their nutrient requirements could be satisfied by mycelial transport" and support the "combination of AMF with no-till agriculture to achieve a genuinely sustainable agriculture". Gianinazzi et al. [17] ensure that "the appropriate management of ecosystem services rendered by AM will impact on natural resource conservation and utilization with an obvious net gain for human society".

\section{Nutraceuticals, Vitamins and Minerals in Mycorrhizal Lettuce Plants}

\subsection{Chlorophylls (Chl)}

Pigments are normal constituents of cells and tissues and perform physiological functions. Chlorophylls (Chl), vital for photosynthesis, are photoreceptors localized in the chloroplasts that allow plants to absorb energy from light. Chlorophyll a $(\mathrm{Chl}$ a) is the unique chlorophyll in higher plants that acts as primary electron donor in the reaction center of photosystems, although it also helps, together with chlorophyll b ( $\mathrm{Chl} \mathrm{b)} \mathrm{and} \mathrm{carotenoids,} \mathrm{to} \mathrm{transfer} \mathrm{energy} \mathrm{in} \mathrm{the} \mathrm{antenna} \mathrm{complex.} \mathrm{In} \mathrm{recent} \mathrm{years,}$ there has been a growing interest in natural and semi synthetic chlorophyll derivatives, not only as food colorants, but also as food supplements due to their potential effect against the development of several chronic diseases and to their anti-inflammatory activity measured in vitro [24].

Numerous researchers [21,25-28] have found increased concentrations of total Chl in leaves of several crops (onion, strawberry, pepper and chickpea) inoculated with different AM species belonging to the genus Glomus ( $G$. mosseae, G. versiforme, G. intraradices, G. etonicatum or G. deserticola). 
Similar results were obtained in Trifoliate Orange, a tree whose fruits are widely used in Oriental medicine as a remedy for allergic inflammation, when it was inoculated with G. mosseae [29]. Selvaraj et al. [30] also observed increased levels of Chl in Pogostemon patchouli, an aromatic herb belonging to the mint family and cultivated for its essential oil used in cosmetics, when it was inoculated with isolates of seven indigenous AMF (Acaulospora scrobiculata, Gigaspora margarita, G. aggregatum, G. geosporum, G. mosseae, Sclerocystis pakistanika and Scutellospora heterogama); however, Chl enhancements varied with the AMF species inoculated.

Similar to the aforementioned studies, Baslam et al. [31-33] reported that the symbiosis of greenhouse grown lettuce plants with AMF resulted in enhanced amounts of $\mathrm{Chl}$ in leaves. However, increases in the levels of $\mathrm{Chl}$ varied depending on the type of lettuce [31,32], the species of AMF associated with roots of lettuce [31,32], the source of $\mathrm{P}$ applied to plants [33] and the season of the year in which lettuces were cultivated [31-33]. For example, compared with the non-inoculated controls, the application of a mixture of Glomus intraradices and $G$. mosseae induced higher enhancements in the levels of both $\mathrm{Chl} \mathrm{a}$ and $\mathrm{Chl} \mathrm{b}$ in the red leaf lettuce Maravilla de Verano than in the green leaf lettuces Cogollos de Tudela and Batavia Rubia Munguía [32]. Moreover, the mixture of $G$. intraradices and $G$. mosseae was more effective than the application of $G$. fasciculatum for inducing the accumulation of $\mathrm{Chl}$ in leaves of the three aforementioned types of lettuces [32]. Furthermore, increases in the levels of total Chl were more evident when lettuces were fertilized with either modified Hewitt's nutrient solution or a water-insoluble (WI) source of $\mathrm{P}$ than when they received single superphosphate (SSP) as $\mathrm{P}$ source [33]. The degree of effectiveness of AMF for improving the contents of $\mathrm{Chl}$ in leaves of greenhouse-grown lettuces was also dependent on the season in which plants were cultivated: The highest contents of total $\mathrm{Chl}$ in leaves of mycorrhizal Maravilla de Verano and Batavia Rubia Munguía were found in autumn [34]. Unfortunately, when lettuce plants were cultivated under optimal irrigation, the greatest improvements in the levels of Chl due to mycorrhizal association were found in outer leaves, which are usually stripped-off before this vegetable is consumed. In contrast, when cultivated with restricted water supply, the highest increments in the amounts of $\mathrm{Chl}$ were observed in inner leaves of both green and red leaf mycorrhizal lettuces [34]. The increased levels of $\mathrm{Chl}$ in mycorrhizal lettuce plants presumably would have contributed to achieve higher photosynthetic rates in the whole plant, thus benefiting both growth of host plants (Figure 1) and the development and functionality of the symbiosis. 
Figure 1. Lactuca sativa (a) var. Longifolia (Cogollos de Tudela); (b) var. Capitata cv. Batavia Rubia Munguía; and (c) var. Capitata cv. Maravilla de Verano, inoculated with either Glomus fasciculatum or a mixture of Glomus intraradices and Glomus mosseae or non-mycorrhizal. Photographs were taken at harvest, 7 weeks after transplanting. Growth conditions as described by Baslam et al. [31].

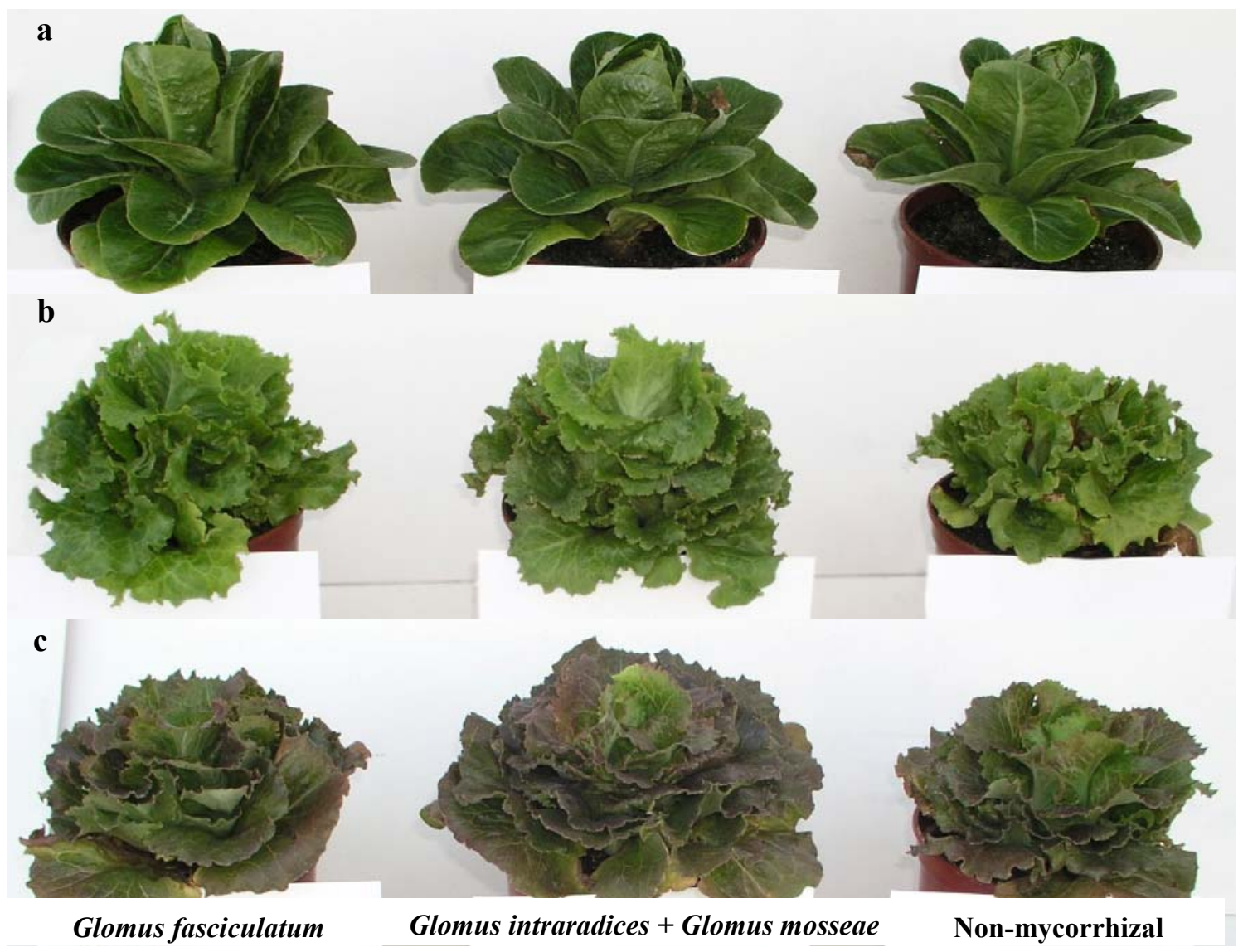

\subsection{Carotenoids}

Carotenoids are pigmented compounds that are uniquely synthesized by higher plants, algae, fungi and bacteria. During photosynthesis, carotenoids present in the thylakoid membrane of chloroplasts harvest light and transfer the absorbed energy to the reaction center of photosystems. Carotenoids also protect $\mathrm{Chl}$ from photo-damage by dissipating the excess of energy and quenching reactive oxygen species (ROS) produced under excess light [35]. Apart from their function in the assembly of photosynthesis, light capture and photoprotection, carotenoids play other essential functions in nature: They promote animal behavior, reproduction and survival, they improve nutrition and human health and they provide substrates for the biosynthesis of plant hormones (e.g., abscisic acid) and signaling molecules (e.g., mycorradicin in the root-mycorrhizal symbiosis) [36]. Carotenoid biosynthesis is regulated throughout the life cycle of a plant with dynamic changes in composition matched to prevailing developmental requirements and in response to external environmental stimuli [37]. Fruits and vegetables constitute the primary sources of carotenoid in human diet and are responsible for their yellow, orange and red colours of some plant organs [5]. Major dietary carotenoids include hydrocarbons, such as $\beta$-carotene, $\alpha$-carotene and lycopene, as well as xanthophylls or oxygen-containing 
carotenoids, including $\beta$-cryptoxanthin, lutein and zeaxanthin. Most carotenoids have provitamin A activity. Vitamin A deficiency is responsible for a number of disorders that range from impaired iron mobilization, growth retardation and blindness to a depressed immune response, as well as increased susceptibility to infectious disease [38]. Apart from their provitamin A activity, carotenoids are considered to have many other biological functions: They are proposed to be efficient scavengers of free radicals, protectors of low density lipoproteins (LDLs) against oxidation and they are believed to prevent cardiovascular diseases, cancer and other chronic diseases that affect human beings [39-41].

It is well-known that AMF can stimulate carotenoid metabolic pathways in plant roots $[19,42,43]$. AM symbiosis activates the plastidial methylerythritole phosphate (MEP) pathway by increasing transcript levels of MEP and carotenoid biosynthetic and cleavage genes [42], which stimulates the production of carotenoids and carotenoid cleavage products including $\mathrm{C}_{13}$ cyclohexenone derivatives (e.g., blumenol), $\mathrm{C}_{14}$ apocarotenoids (e.g., mycorradicin) and strigolactones. However, few analyses have targeted final crop products of the aerial part in mycorrhizal plants used for food or medicinal purposes. Some of these scarce studies are those performed by Ulrichs et al. [44], who measured increased quantity of lycopene and $\beta$-carotene in fruits of tomato inoculated with Glomus sp. and those carried out by Mena-Violante et al. [45], who reported enhanced carotenoid content in chile ancho (Capsicum annuum L. cv. San Luis) plants inoculated with G. fasciculatum and subjected to drought. In a recent study, Giovannetti et al. [46] found that $G$. intraradices can enhance nutritional and nutraceutical value of tomato fruits without production of mutagenic compounds. One explanation for the enhanced levels of carotenoids in fruits of mycorrhizal plants is that AMF can induce changes in the chloroplasts. It is known that chloroplasts of mycorrhizal plants can have higher and more numerous plastoglobuli [47], the subcellular compartment where carotenoids are mainly localized during the chloroplast to chromoplast transformation.

According to Baslam et al. [32], $\beta$-carotene was the carotenoid most accumulated in leaves of greenhouse-grown lettuces, although its distribution between outer and inner leaves differed among types of lettuce. Such a distribution was not related to the distinction between green and red leaf lettuces. In fact, the green leaf Cogollos de Tudela (var. Longifolia) and the red leaf Maravilla de Verano (var. Capitata) had higher levels of $\beta$-carotene in inner than in outer leaves. In contrast, the green leaf Batavia Rubia Munguía (another cultivar belonging to the var. Capitata) accumulated greater levels of $\beta$-carotene in the external than in internal leaves. The distribution of main xanthophylls between outer and inner leaves followed a similar pattern. Low levels of pigments in the internal leaves of Batavia Rubia Munguía may indicate an acclimation pattern [48] to the low light incidence on leaves that form a round and dense lettuce head. The levels of main carotenoids significantly increased after the inoculation of the aforementioned types of lettuce with AMF [32]. However, the most relevant enhancements in the levels of carotenoids were observed in outer leaves, with the exception of Cogollos de Tudela, the variety that formed a less dense head. After applying a mixture of $G$. mosseae and G. intraradices to the red leaf Maravilla de Verano levels of carotenoids in the outer leaves were four to eight times higher than those found in comparable leaves of their non-inoculated control plants. Zeaxanthin was the xanthophyll whose levels in mycorrhizal Maravilla de Verano were eight times higher than those measured in the non-inoculated plants, which indicates that lettuces associated with AMF improved their ability for absorbing blue light and quenching reactive oxygen species thus reducing the amount of light that induces oxidative damage [35]. On the 
other hand, consumption of mycorrhizal Maravilla de Verano in the diet would provide increased levels of violaxanthin, the pigment whose deficiency provokes macular degeneration and irreversible loss of vision [49], enhanced contents of $\beta$-carotene, inversely related to the risk of cardiovascular diseases and certain cankers, and improved amount of lutein, which prevents disorders related to the eye [4]. Similar conclusions could be inferred from the results obtained when applied mycorrhizal inocula to the green leaf types of lettuce, Batavia Rubia Munguía and Cogollos de Tudela [32]. Increased contents of carotenoids in leaves of Maravilla de Verano after inoculating AMF contrast with decreased levels of neoxanthin, lutein and $\beta$-carotene observed in other types of red leaf lettuces after applying supplemental UV radiation in the greenhouse [50].

Nevertheless, the effect of mycorrhizal symbiosis on carotenoid accumulation may vary according to environmental parameters and cultural practices. For example, contents of total carotenoids in mycorrhizal lettuces increased when plants were subjected to different kinds and degrees of water deficit [34]. This additive effect between AMF and water restriction was mainly observed in the external leaves of the green leaf lettuce Batavia Rubia Munguía and in the internal leaves of the red leaf lettuce Maravilla de Verano. The source of phosphorus nutrition applied to lettuce plants also modified the effectiveness of AMF in improving the levels of carotenoids: the positive effect of AMF was more evident when plants were fertilized with either modified Hewitt's nutrient solution or a water insoluble (WI) source of $\mathrm{P}$ than when they received the water soluble single superphosphate (SSP) [33]. Although the benefits of carbon dioxide $\left(\mathrm{CO}_{2}\right)$ supplementation on plant growth and production within the greenhouse environment have been well understood for many years, the levels of total carotenoids in both external and internal leaves decreased when Batavia Rubia Munguía and Maravilla de Verano were grown under increased atmospheric $\mathrm{CO}_{2}$ concentrations (700 ppm) in the greenhouse [51].

\subsection{Phenolic Compounds}

Phenolic compounds are SMs that constitute one of the most common and widespread groups of substances in plants [52]. They are characterized by the presence of at least one benzene ring, to which is directly attached at least one hydroxyl group, free or bound to another function (esters, methyl esters, glycosides, among others). As a general rule, the terms phenolic and polyphenol refers to all secondary natural metabolites arising biogenetically from the phenylpropanoid and flavonoid pathways. The key enzyme in this biosynthetic pathway is phenylalanine ammonia-lyase (PAL), which can be induced by different stresses [52]. Plants need phenolic compounds for pigmentation, growth, UV sunscreens, reproduction and resistance to pathogens [53]. These compounds protect plants against oxidative damage and perform the same function in the human body. A clear relationship has been found between antioxidant activity and presence of phenols in common vegetables and fruits [54-56].

AMF colonization can alter or enhance the production of phenolics within the host plant. Some studies have reported an improvement of phenolic content in olive trees inoculated with a mixture of three different AMF, G. invermaium, Acaulospora laevis and Scutellospora calospora [57], in mycorrhizal plants of "sweet" basil [58,59] as well as in strawberry inoculated with G. intraradices [60].

Our experiments with non-mycorrhizal and mycorrhizal lettuce plants corroborated these results. Baslam et al. [31] observed that greenhouse grown lettuces belonging to the variety Longifolia 
(Cogollos de Tudela) had similar levels of total soluble phenolics in outer and inner leaves when they had not established symbiotic association with AMF. However, the symbiosis of Cogollos de Tudela with AMF induced the accumulation of soluble phenolic compounds in external leaves. In contrast, the application of AMF to lettuces belonging to the variety Capitata only improved the amount of soluble phenolics significantly when plants received restricted water supply [34] or when they were cultivated in winter [33]. Once more, the source of phosphorus nutrition applied to lettuces also influenced the levels of soluble phenolic compounds in leaves regardless plants were or not associated with AMF [33]. Insufflations of $\mathrm{CO}_{2}$ in the greenhouse were effective at inducing the accumulation of soluble phenolics but only in non-mycorrhizal lettuces [51]. Baslam et al. [51] hypothesized that in mycorrhizal lettuces grown under elevated $\mathrm{CO}_{2}$ a relevant quantity of photoassimilates was used for both enhancing shoot growth and spreading mycorrhizal colonization in detriment to the secondary metabolism. Apart from the nutritional point of view, increased levels of these C-based SMs may have improved the defense capacity of lettuce plants against herbivores and/or pathogenic organisms [61].

The relationship between AMF colonization and the phenolic compounds produced in plants remains poorly understood. However, as hypothesized by Toussaint et al. [58], higher $\mathrm{N}$ assimilation in mycorrhizal plants might contribute to the higher production of phenylalanine ammonia lyase (PAL), a key enzyme involved in the synthesis of many phenolic compounds. Moreover, plant phenolic compounds are potential candidates as signals during mycorrhizal formation. Some reports show that flavonoids, together with the aforementioned strigolactones, can exert a positive effect on hyphal growth during the establishment of the AMF symbiosis [62].

Anthocyanins belong to the large family of phenolic compounds collectively known as flavonoids. The molecule of anthocyanins consists of an anthocyanidin (the aglycone chromophore) bonded to one or more glycosides, which are produced with a biochemical cost to the plant. Anthocyanins are water-soluble pigments that can provide red to blue colors in flowers, fruits, leaves, and storage organs [63]. The synthesis of these phenolic compounds in plants may also be induced or modulated by several environmental factors, such as light quality and quantity, extreme temperatures, osmotic stress, mineral and $\mathrm{pH}$ imbalances, mechanical damage, herbivore and pathogen attacks, pollution and application of herbicides [64], and they are known to play a crucial role as inducers of antioxidant responses in plants against biotic and abiotic stresses [64,65]. Anthocyanins have also been recognized as beneficial compounds for human health. Many pharmacological benefits have derived from their antioxidant, antimutagenic, antiallergic, anti-inflammatory, antiviral and anticarcinogenic properties [66].

The influence of AMF on the levels of anthocyanins in host plants has been studied in different crops, such as Cherry tomato inoculated with G. etunicatum [67], different cultivars of the culinary herb commonly known as "basil" [59] and strawberry [60] associated with G. intraradices. In all these studies, results shown that mycorrhizal plants had increased concentrations of total anthocyanins in leaves, stems and/or fruits compared to their respective non-mycorrhizal controls. Likewise, red leaf lettuces, such as Maravilla de Verano, have higher amounts of anthocyanins in leaves than green leaf lettuces, such as Batavia Rubia Munguía and Cogollos de Tudela. However, when associated with $\mathrm{AMF}$, leaves of some green leaf types of lettuces (e.g., Batavia Rubia Munguía) can accumulate similar levels of anthocyanins to those found in leaves of non-mycorrhizal red leaf types of lettuces (e.g., Maravilla de Verano) [31]. The levels of anthocyanins also increased significantly in the red leaf lettuce Maravilla de Verano when associated with AMF, with the increases being more relevant when 
a mixture of $G$. mosseae and $G$. intraradices was applied than when G. fasciculatum was used [31]. The effectiveness of AMF for inducing the accumulation of anthocyanins in leaves of lettuce plants also depends on the season of the year when this vegetable crop is grown: Differences in the contents of anthocyanins between non-mycorrhizal and mycorrhizal lettuces were greater when plants were cultivated in summer [31] than when grown in winter [33]. Other cultural practices, such as the irrigation regime applied to greenhouse grown lettuce plants, can also affect the levels of anthocyanins. The imposition of a continuous and moderate drought stress to non-mycorrhizal lettuce plants induced the accumulation of anthocyanins in both outer and inner leaves of the green leaf lettuce Batavia Rubia Munguía but had no effect on the amounts of these phenolic compounds in leaves of the red leaf type Maravilla de Verano [34]. However, amounts of anthocyanins always increased in mycorrhizal plants cultivated with restricted water supply: In mycorrhizal Batavia Rubia Munguía enhancements were more evident in inner than in outer leaves; in mycorrhizal Maravilla de Verano the most relevant increases occurred in external leaves [34]. Insufflations of $\mathrm{CO}_{2}$ in the greenhouse can modify the concentrations of anthocyanins in leaves of lettuce plants, but results may be different in green and red leaf types of lettuces and also in non-mycorrhizal and mycorrhizal plants [51]. Elevated $\mathrm{CO}_{2}$ (700 ppm) induced the accumulation of these phenolic compounds in outer leaves of the green leaf lettuce Batavia Rubia Munguía but only when plants were not associated with AMF. In contrast, increased atmospheric $\mathrm{CO}_{2}$ had no effect on the levels of anthocyanins in leaves of the red leaf lettuce Maravilla de Verano when not associated with AMF. In mycorrhizal Maravilla de Verano, elevated $\mathrm{CO}_{2}$ clearly decreased the contents of anthocyanins in outer leaves and moderately enhanced the amount of anthocyanins in inner leaves.

\subsection{Vitamins}

L-Ascorbic acid (for which the generic term is vitamin C) is a multifunctional compound in both plants and animals. This metabolite is one of the most abundant in green leaves. In favorable conditions, it represents $10 \%$ of the total soluble carbohydrate pool [68]. Vitamin C influences mitosis and cell growth in plants. It is also an important cofactor for violaxanthin de-epoxidase and dioxygenase type enzymes involved in the synthesis of hydroxyproline, ethylene, gibberellic acid, anthocyanins and a number of other secondary metabolites. Furthermore, vitamin $\mathrm{C}$ is already known to be an antioxidant. It protects cells and organelles from oxidative damage by scavenging ROS produced by aerobic metabolic processes, such as photosynthesis and respiration, or by environmental stresses including drought, cold and excess of light [68-71]. Vitamin $\mathrm{C}$ is one of the most important vitamins in fruits and vegetables for human nutrition. More than $90 \%$ of the vitamin $\mathrm{C}$ in human beings, who are incapable of synthesizing ascorbic acid due to the lack of the enzyme L-gulono-1,4-lactone oxidase, is supplied by fruits and vegetables in the diet. Ascorbic acid (AA) is the principal biologically active form, but L-dehydroascorbic acid (DHA), an oxidation product, also exhibits biological activity. Since DHA can be easily converted into AA in the human body, it is important to measure both AA and DHA in fruits and vegetables for vitamin $\mathrm{C}$ activity [72]. Vitamin $\mathrm{C}$ might protect against oxidative stress and thereby decrease cancer risk [73,74]. For these reasons, there is considerable interest in enhancing the ascorbate content in fruits and vegetables consumed in the human diet. 
In lettuce, the distribution of total ascorbate between outer and inner leaves of plants can be distinct in different varieties or cultivars. While levels of total ascorbate were similar in outer and inner leaves of lettuces belonging to the variety Capitata, in the variety Longifolia external leaves showed significantly higher concentrations of total ascorbate than internal leaves did [31]. The application of mycorrhizal inocula to lettuce plants cultivated under an optimal irrigation regime slightly increased the amount of total ascorbate in leaves, with G. fasciculatum being more effective than the mixture of $G$. mosseae and G. intraradices in enhancing the levels of vitamin C [31]. According to Qiang-Sheng et al. [75], AMF symbiosis induced the accumulation of ascorbate in leaves of both well watered and water stressed trifoliate orange seedlings. Although Oh et al. [76] concluded that the adaptation of lettuce plants to water stress was associated with the activation of the enzyme L-galactose dehydrogenase (L-GalDH) implied in the biosynthesis of ascorbic acid, Baslam and Goicoechea [34] observed no significant effects of different types and degrees of water deficit on the concentrations of total ascorbate (reduced ascorbate + dehydroascorbate) pool in the two cultivars Batavia Rubia Munguía and Maravilla de Verano, regardless of whether they were or not associated with AMF. However, ratio between reduced ascorbate (ASC) and dehydroascorbate (DHA) changed in plants undergoing restricted irrigation, with the changes being mainly dependent on both cultivar of lettuce and mycorrhizal symbiosis. Redox state can be defined as the ratio between reduced and oxidized molecules within a pool and the most abundant contributor to general redox metabolism in plant cells is ascorbate [77]. In non-mycorrhizal Maravilla de Verano the relative abundance of ASC (high ASC/DHA) in plants subjected to maintained water deficits suggested that these redox metabolites cooperated in scavenging harmful concentrations of ROS in cells of leaves by fueling the ASC-glutathione cycle [37]. However, as well as the "big three" antioxidants, ascorbate (ASC), glutathione (GSH) and the pyridine nucleotides NADH and NADPH, plants contain many distinct redox-active compounds, including phenolics and carotenoids, that actively contribute to the global cellular redox state [77]. Declines in the ratio ASC/DHA in non-mycorrhizal Batavia Rubia Munguía and, especially, in all mycorrhizal lettuce plants when subjected to different types and degrees of water deficits [34] could be partially overcome by enhancements in the concentrations of phenolics and carotenoids previously explained. Moreover, AM symbiosis can also increase the activity of antioxidant enzymes in lettuce plants, as described by Kohler et al. [78]. In any case, whereas at the outset of plant stress, ROS were only considered as damaging the cell components, the view nowadays has shifted to ROS being an integrative part of cell signaling metabolism modulated by the cellular redox state, leading to different responses related to programmed cell death, gene expression, plant defense or plant development [77].

Tocopherols and tocotrienols, collectively known as tocochromanols, are lipid-soluble molecules that belong to the group of vitamin E compounds and are essential in the human diet. Tocopherols may play important roles in plants beyond their antioxidant function in photosynthetic membranes. Plants deficient in tocopherols show alterations in germination, export of photoassimilates, leaf senescence and responses to abiotic stresses [79]. Tocochromanols can be only synthesized by plants and other oxygenic, photosynthetic organisms. Supplementation of the human diet with vitamin E contained in fruits and vegetables is considered to provide health benefits against cardiovascular diseases through its antioxidant activity, the prevention of lipoprotein oxidation and the inhibition of platelet 
aggregation [80,81]. Moreover, Lira et al. [82] suggested that vitamin E supplementation could be effective for avoiding obesity.

According to results obtained by Baslam et al. [32], greenhouse grown lettuces had quite similar concentrations of tocopherol ( $\alpha$-tocopherol $+(\beta-\gamma)$-tocopherol) in outer and inner leaves when they were not associated with any AMF. In general terms, mycorrhizal symbiosis induced the accumulation of tocopherol in leaves. To our knowledge, there are no previous reports on the effect of AM symbiosis on the accumulation of tocopherol in plant tissues. According to our results, the most relevant increases in the amount of tocopherols were observed in external leaves of any variety or cultivar of lettuce after applying a mixture of $G$. mosseae and $G$. intraradices. However, among all mycorrhizal plants, the highest levels of tocopherols were found in external leaves of the red leaf lettuce Maravilla de Verano. Lizarazo et al. [83] concluded that increased levels of tocopherols with leaf ageing represent a general trait in plants. Since AMF can shorten the life cycle of their host plants [84], the possible different phenological stage of mycorrhizal and non-mycorrhizal lettuces could explain why the outer leaves of mycorrhizal lettuces had greater amounts of tocopherols than the external leaves of their non-mycorrhizal controls [32].

\subsection{Minerals}

The level of minerals in vegetables depends on a number of factors including genetic properties of the crop species, climatic conditions, soil characteristics and the degree of maturity of the plant at the moment of harvesting [85]. As vegetables constitute the main source of minerals in the human diet, one of the most important challenges for agriculture, besides enhancing food production, is to provide almost all the essential minerals and organic nutrients to humans for maintenance of health and proper organ function. Humans need more than 22 mineral elements. Some are required in large amounts while others, such as $\mathrm{Fe}, \mathrm{Zn}, \mathrm{Cu}, \mathrm{I}$ and $\mathrm{Se}$, are required in trace amounts [86] but their absence renders human life impossible. Concentrations of several essential elements in modern crops are insufficient for optimal human nutrition, thus contributing to the huge "hidden hunger" problem [87]. This is the case of iron (Fe), whose deficiency affects more than 3.5 billion people, mostly in the developing world and impairs the cognitive development of children, causes productivity and educational losses and increases morbidity and maternal mortality [88]. Other important examples are zinc ( $\mathrm{Zn}$ ), a micronutrient whose levels of intake in the diet may be inadequate for nearly half of the world's population [89] and copper $(\mathrm{Cu})$, essential for human health but consumed in inadequate quantities in some developed countries, such as the United Kingdom or the Unites States [90].

It is well known that AMF can increase the uptake of micronutrients and other mineral nutrients with low mobility including the aforementioned $\mathrm{Fe}$ [91], $\mathrm{Zn}$ [92] and $\mathrm{Cu}$ [93]. In greenhouse grown lettuces cultivated with optimal irrigation, mycorrhizal symbiosis improved the levels of $\mathrm{Cu}$ and Fe [31] but the effect was dependent on lettuce cultivar and the source of P applied to plants [33]. Azcón et al. [94] described that mycorrhizal lettuce plants with high availability of $\mathrm{N}$ and $\mathrm{P}$ in the soil reduced the content of macro and micronutrients in their tissues. However, when plants were fertilized with a low level of both, $\mathrm{P}$ and $\mathrm{N}$, nearly all the macro and micronutrients $(\mathrm{P}, \mathrm{K}, \mathrm{Ca}, \mathrm{Mg}, \mathrm{Cu}, \mathrm{Fe}, \mathrm{Mn}$, $\mathrm{Zn}$ and S) were enhanced by AMF colonization. Our results showed that the higher size achieved by mycorrhizal lettuces (Figure 1) produced a dilution effect on the concentrations of some mineral 
nutrients in leaf tissues. Goicoechea et al. [95] found that AMF may be more beneficial for the mineral nutrition of host plants under water deficit than when plants grown with adequate water supply. This same idea can be inferred from data included in Table 1: The association of the green leaf lettuce Batavia Rubia Munguía with AMF enhanced the concentrations of $\mathrm{N}, \mathrm{P}, \mathrm{Cu}$ and $\mathrm{Fe}$ in inner leaves when plants were cultivated under a water regime equivalent to $2 / 3$ of field capacity; moreover, the levels of $\mathrm{P}$ in internal and $\mathrm{Fe}$ in external leaves of mycorrhizal plants were greater than those of non-mycorrhizal plants when lettuces received a water content equivalent to $1 / 2$ of field capacity. Enhanced $\mathrm{P}$ nutrition is considered as one of the major mechanisms by which AMF can improve the water status of their host plants [96]. However, this behavior was not observed in the red leaf lettuce Maravilla de Verano (Table 2), which indicates that results are highly dependent on the type of lettuce. Similarly, under saline conditions, Zuccarini [97] observed that mycorrhizal symbiosis stimulated the absorption of $\mathrm{K}$ and $\mathrm{P}$ of lettuce Meraviglia d'Inverno.

In an opinion paper dealing with the topic of rising atmospheric $\mathrm{CO}_{2}$, Loladze [98] linked high concentrations of atmospheric $\mathrm{CO}_{2}$ with plant stoichiometry and quality of human nutrition and hypothesized that elevated $\mathrm{CO}_{2}$ could both reduce the ratio between nutritional and caloric values of crops and intensify the already acute problem of micronutrient malnutrition in the developing world. In this context of rising atmospheric $\mathrm{CO}_{2}$, AMF are predicted to be important in defining plant responses to elevated $\mathrm{CO}_{2}$ concentrations. As elevated $\mathrm{CO}_{2}$ affects photosynthetic rates, it would also influence $\mathrm{C}$ supply to AMF colonizing roots [99]. In turn, AMF may diminish the plant nutrient limitation associated with enhanced photosynthetic rates [100]. In fact, lower concentrations of $P$ in tissues of plants when grown under elevated $\mathrm{CO}_{2}$ can be alleviated by the formation of AMF and any improvements in plant $\mathrm{N}$ nutrition resulting from the formation of AMF may be also important in determining plant responses to atmospheric $\mathrm{CO}_{2}$ enrichment [61]. However, despite this optimistic approach on the potential role of AMF in a context of rising atmospheric $\mathrm{CO}_{2}$, data obtained by Baslam et al. [51] showed that the accumulation of some mineral nutrients induced by AMF in leaves of greenhouse grown lettuces cultivated at ambient $\mathrm{CO}_{2}$ diminished or even disappeared under elevated $\mathrm{CO}_{2}$ (700 ppm), as happened with some SMs. Moreover, plant stoichiometry also was modified under elevated $\mathrm{CO}_{2}$; in general terms, the association of lettuces with AMF together with the exposure of plants to elevate $\mathrm{CO}_{2}$ increased the ratio between $\mathrm{C}$ and other mineral nutrients. 
Table 1. Concentrations of mineral nutrients in outer and inner leaves of lettuces cv. Batavia Rubia Munguía, non-inoculated (NM) or inoculated (M) with a mixture of Glomus intraradices and Glomus mosseae (AMF), and cultivated with a water regimen equivalent to either $2 / 3(2 / 3$ FC) or $1 / 2(1 / 2$ FC) of field capacity. Values are means $(n=3) \pm$ SE. Data were subjected to a three-factor ANOVA and LSD post hoc test. Within each column, data followed by the same letter indicate that values did not differ significantly $(p \leq 0.05)$. ns: not significant;

* significant at $p \leq 0.05 ; * *$ significant at $p \leq 0.01 ; * *$ significant at $p \leq 0.001$; FW: Fresh weight; PL: Position of leaves.

\begin{tabular}{|c|c|c|c|c|c|c|c|c|c|c|c|}
\hline \multirow{2}{*}{\multicolumn{3}{|c|}{ Treatments }} & $\mathbf{N}$ & $\mathbf{C a}$ & $\mathbf{K}$ & $\mathbf{P}$ & Mg & $\mathbf{C u}$ & $\mathbf{Z n}$ & $\mathbf{F e}$ & Mn \\
\hline & & & \multicolumn{5}{|c|}{ 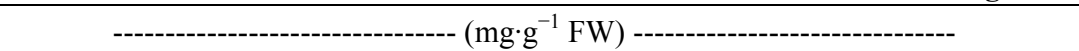 } & \multicolumn{4}{|c|}{ 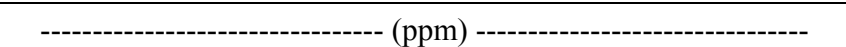 } \\
\hline \multirow{5}{*}{$2 / 3$ FC } & r & Outer leaves & $2.6 \pm 0.12 \mathrm{~cd}$ & $0.67 \pm 0.02 \mathrm{bc}$ & $6.5 \pm 0.16 \mathrm{bc}$ & $0.08 \pm 0.00 \mathrm{e}$ & $0.28 \pm 0.01 \mathrm{c}$ & $0.32 \pm 0.06 \mathrm{bc}$ & $4.4 \pm 0.80 \mathrm{ab}$ & $8.3 \pm 0.96 \mathrm{~b}$ & $17.8 \pm 1.02 \mathrm{~b}$ \\
\hline & NM & Inner leaves & $2.5 \pm 0.12 \mathrm{~d}$ & $0.36 \pm 0.03 \mathrm{~d}$ & $4.6 \pm 0.28 \mathrm{e}$ & $0.15 \pm 0.01 \mathrm{c}$ & $0.14 \pm 0.01 \mathrm{e}$ & $0.08 \pm 0.02 \mathrm{e}$ & $2.8 \pm 0.29 \mathrm{~cd}$ & $4.1 \pm 0.50 \mathrm{~d}$ & $7.1 \pm 0.60 \mathrm{e}$ \\
\hline & $\mathbf{M}$ & Outer leaves & $3.0 \pm 0.16 b c$ & $0.65 \pm 0.08 \mathrm{c}$ & $6.5 \pm 0.47 \mathrm{bc}$ & $0.10 \pm 0.00 \mathrm{e}$ & $0.30 \pm 0.03 b c$ & $0.41 \pm 0.01 \mathrm{ab}$ & $2.3 \pm 0.30 \mathrm{~d}$ & $7.2 \pm 0.42 \mathrm{bc}$ & $12.8 \pm 1.31 \mathrm{c}$ \\
\hline & $\mathbf{M}$ & Inner leaves & $3.2 \pm 0.25 \mathrm{~b}$ & $0.40 \pm 0.03 \mathrm{~d}$ & $4.9 \pm 0.27 \mathrm{de}$ & $0.22 \pm 0.01 \mathrm{a}$ & $0.19 \pm 0.01 \mathrm{de}$ & $0.23 \pm 0.03 \mathrm{~cd}$ & $3.0 \pm 0.16 \mathrm{~cd}$ & $6.4 \pm 0.21 \mathrm{c}$ & $6.6 \pm 0.76 \mathrm{e}$ \\
\hline & NM & Outer leaves & $3.7 \pm 0.18 \mathrm{a}$ & $0.83 \pm 0.02 \mathrm{a}$ & $8.7 \pm 0.44 \mathrm{a}$ & $0.11 \pm 0.00 \mathrm{~d}$ & $0.36 \pm 0.02 \mathrm{ab}$ & $0.51 \pm 0.07 \mathrm{a}$ & $5.6 \pm 0.32 \mathrm{a}$ & $9.5 \pm 0.36 \mathrm{~b}$ & $25.7 \pm 1.31 \mathrm{a}$ \\
\hline \multirow[t]{10}{*}{$1 / 2$ FC } & & Inner leaves & $3.4 \pm 0.16 \mathrm{ab}$ & $0.46 \pm 0.05 \mathrm{~d}$ & $5.8 \pm 0.38 \mathrm{~cd}$ & $0.20 \pm 0.00 \mathrm{~b}$ & $0.17 \pm 0.02 \mathrm{de}$ & $0.18 \pm 0.04 \mathrm{de}$ & $3.7 \pm 0.52 \mathrm{bc}$ & $5.5 \pm 0.38 \mathrm{~cd}$ & $11.4 \pm 1.53 \mathrm{~cd}$ \\
\hline & M & Outer leaves & $3.4 \pm 0.08 \mathrm{ab}$ & $0.77 \pm 0.04 \mathrm{ab}$ & $7.9 \pm 0.12 \mathrm{ab}$ & $0.13 \pm 0.01 \mathrm{~cd}$ & $0.38 \pm 0.03 \mathrm{a}$ & $0.50 \pm 0.07 \mathrm{a}$ & $3.7 \pm 0.23 \mathrm{bc}$ & $14.9 \pm 1.65 \mathrm{a}$ & $17.5 \pm 0.43 \mathrm{~b}$ \\
\hline & & Inner leaves & $3.5 \pm 0.34 \mathrm{ab}$ & $0.42 \pm 0.04 \mathrm{~d}$ & $5.3 \pm 0.64 \mathrm{de}$ & $0.22 \pm 0.02 \mathrm{a}$ & $0.20 \pm 0.02 \mathrm{de}$ & $0.15 \pm 0.04 \mathrm{de}$ & $3.4 \pm 0.40 \mathrm{bc}$ & $7.1 \pm 0.35 b c$ & $9.4 \pm 0.85 \mathrm{de}$ \\
\hline & & Drought (degree) & $* * *$ & $* *$ & $* * *$ & $* *$ & $*$ & $\mathrm{~ns}$ & $* *$ & ns & $* * *$ \\
\hline & & AMF & ns & ns & ns & $* * *$ & ns & ns & $* *$ & ns & $* * *$ \\
\hline & & Position of leaves (PL) & ns & $* * *$ & $* * *$ & $* * *$ & $* * *$ & $* * *$ & $*$ & $*$ & $* * *$ \\
\hline & & Drought $\times$ AMF & $*$ & ns & ns & ns & ns & ns & ns & ns & ns \\
\hline & & Drought $\times \mathbf{P L}$ & ns & ns & ns & ns & ns & ns & ns & ns & ns \\
\hline & & $\mathbf{A M F} \times \mathbf{P L}$ & ns & ns & ns & $*$ & ns & ns & $* *$ & ns & ** \\
\hline & & Drought $\times \mathbf{A M F} \times \mathbf{P L}$ & ns & ns & ns & ns & ns & ns & ns & ns & ns \\
\hline
\end{tabular}


Table 2. Concentrations of mineral nutrients in outer and inner leaves of lettuces cv. Maravilla de Verano (MV), non-inoculated (NM) or inoculated (M) with a mixture of Glomus intraradices and G. mosseae (AMF), and cultivated with a water regimen equivalent to either 2/3 $(2 / 3$ FC) or $1 / 2(1 / 2$ FC) of field capacity. Values are means $(n=3) \pm$ SE. Data were subjected to a three-factor ANOVA and LSD post hoc test. Within each column, data followed by the same letter indicate that values did not differ significantly $(p \leq 0.05)$. ns, not significant;

* significant at $p \leq 0.05 ;{ }^{* *}$ significant at $p \leq 0.01 ; * *$ significant at $p \leq 0.001$; FW: Fresh weight; PL: Position of leaves.

\begin{tabular}{|c|c|c|c|c|c|c|c|c|c|c|c|}
\hline & \multirow{2}{*}{\multicolumn{2}{|c|}{ Treatments }} & $\mathbf{N}$ & Ca & K & $\mathbf{P}$ & Mg & $\mathbf{C u}$ & Zn & $\mathrm{Fe}$ & Mn \\
\hline & & & \multicolumn{5}{|c|}{------------------------------- $\left(\mathrm{mg} \mathrm{g}^{-1} \mathrm{FW}\right)$----------------------- } & \multicolumn{4}{|c|}{-------------------------------- (ppm ) --------------------------- } \\
\hline \multirow{4}{*}{$2 / 3 \mathrm{FC}$} & \multirow{2}{*}{ NM } & Outer leaves & $2.5 \pm 0.19 \mathrm{~d}$ & $0.90 \pm 0.02 \mathrm{ab}$ & $6.1 \pm 0.12 \mathrm{a}$ & $0.08 \pm 0.00 \mathrm{~b}$ & $0.26 \pm 0.01 \mathrm{~b}$ & $0.20 \pm 0.04 \mathrm{a}$ & $2.2 \pm 0.12 \mathrm{c}$ & $4.9 \pm 0.72 \mathrm{c}$ & $18.0 \pm 0.95 b$ \\
\hline & & Inner leaves & $2.9 \pm 0.12 b c$ & $0.55 \pm 0.03 \mathrm{c}$ & $4.4 \pm 0.15 b$ & $0.19 \pm 0.02 \mathrm{a}$ & $0.16 \pm 0.01 \mathrm{~d}$ & $0.18 \pm 0.03 \mathrm{ab}$ & $3.0 \pm 0.12 \mathrm{~b}$ & $6.3 \pm 0.31 b c$ & $7.9 \pm 0.06 \mathrm{~d}$ \\
\hline & \multirow{2}{*}{$\mathbf{M}$} & Outer leaves & $2.6 \pm 0.29 \mathrm{~cd}$ & $0.94 \pm 0.02 \mathrm{ab}$ & $6.7 \pm 0.41 \mathrm{a}$ & $0.10 \pm 0.00 \mathrm{~b}$ & $0.28 \pm 0.02 \mathrm{ab}$ & $0.12 \pm 0.04 \mathrm{~b}$ & $2.0 \pm 0.27 \mathrm{c}$ & $4.8 \pm 0.41 \mathrm{c}$ & $13.8 \pm 1.82 \mathrm{c}$ \\
\hline & & Inner leaves & $2.8 \pm 0.15 \mathrm{bcd}$ & $0.57 \pm 0.03 \mathrm{c}$ & $4.3 \pm 0.18 \mathrm{~b}$ & $0.19 \pm 0.01 \mathrm{a}$ & $0.19 \pm 0.01 \mathrm{~cd}$ & $0.17 \pm 0.04 \mathrm{ab}$ & $3.0 \pm 0.16 \mathrm{~b}$ & $5.6 \pm 0.33 \mathrm{bc}$ & $7.2 \pm 0.35 \mathrm{~d}$ \\
\hline \multirow{11}{*}{$1 / 2 \mathrm{FC}$} & NM & Outer leaves & $2.8 \pm 0.13 \mathrm{bcd}$ & $0.99 \pm 0.09 \mathrm{a}$ & $6.4 \pm 0.29 \mathrm{a}$ & $0.10 \pm 0.01 \mathrm{~b}$ & $0.34 \pm 0.04 \mathrm{a}$ & $0.19 \pm 0.04 \mathrm{a}$ & $3.4 \pm 0.31 \mathrm{~b}$ & $6.3 \pm 0.83 b c$ & $22.5 \pm 1.58 \mathrm{a}$ \\
\hline & \multirow{3}{*}{$\mathbf{M}$} & Inner leaves & $3.8 \pm 0.41 \mathrm{a}$ & $0.79 \pm 0.15 b$ & $5.9 \pm 0.63 \mathrm{a}$ & $0.23 \pm 0.04 \mathrm{a}$ & $0.26 \pm 0.03 \mathrm{~b}$ & $0.18 \pm 0.03 a b$ & $5.4 \pm 0.65 \mathrm{a}$ & $7.5 \pm 0.91 \mathrm{a}$ & $13.2 \pm 1.26 \mathrm{c}$ \\
\hline & & Outer leaves & $2.6 \pm 0.04 \mathrm{~cd}$ & $0.82 \pm 0.01 \mathrm{~b}$ & $6.5 \pm 0.11 \mathrm{a}$ & $0.09 \pm 0.00 \mathrm{~b}$ & $0.28 \pm 0.01 \mathrm{ab}$ & $0.16 \pm 0.04 \mathrm{ab}$ & $2.0 \pm 0.23 \mathrm{c}$ & $6.6 \pm 0.72 \mathrm{abc}$ & $15.0 \pm 0.87 \mathrm{c}$ \\
\hline & & Inner leaves & $3.2 \pm 0.51 \mathrm{ab}$ & $0.57 \pm 0.06 \mathrm{c}$ & $4.3 \pm 0.50 \mathrm{~b}$ & $0.19 \pm 0.02 \mathrm{a}$ & $0.19 \pm 0.02 \mathrm{~cd}$ & $0.19 \pm 0.21 \mathrm{a}$ & $3.1 \pm 0.28 \mathrm{~b}$ & $6.9 \pm 0.74 \mathrm{ab}$ & $8.5 \pm 1.16 \mathrm{~d}$ \\
\hline & \multicolumn{2}{|c|}{ Drought (degree) } & ns & $\mathrm{ns}$ & $\mathrm{ns}$ & ns & ns & ns & $* *$ & $*$ & $* *$ \\
\hline & \multicolumn{2}{|c|}{ AMF } & ns & $\mathrm{ns}$ & $\mathrm{ns}$ & $\mathrm{ns}$ & ns & ns & $* * *$ & ns & $* * *$ \\
\hline & \multicolumn{2}{|c|}{ Position of leaves (PL) } & $*$ & $* * *$ & $* * *$ & $* * *$ & $* *$ & ns & $* * *$ & ns & $* * *$ \\
\hline & \multicolumn{2}{|c|}{ Drought $\times$ AMF } & ns & $*$ & $\mathrm{~ns}$ & $\mathrm{~ns}$ & $*$ & ns & $* *$ & $\mathrm{~ns}$ & $*$ \\
\hline & \multicolumn{2}{|c|}{ Drought $\times$ PL } & ns & ns & $\mathrm{ns}$ & ns & $\mathrm{ns}$ & ns & ns & ns & ns \\
\hline & \multicolumn{2}{|c|}{$\mathbf{A M F} \times \mathbf{P L}$} & $\mathrm{ns}$ & ns & ns & ns & $\mathrm{ns}$ & ns & $\mathrm{ns}$ & ns & $\mathrm{ns}$ \\
\hline & \multicolumn{2}{|c|}{ Drought $\times \mathbf{A M F} \times \mathbf{P L}$} & ns & ns & ns & $\mathrm{ns}$ & ns & ns & ns & $\mathrm{ns}$ & ns \\
\hline
\end{tabular}




\section{Conclusions and Future Prospects}

The application of AMF appears as a feasible alternative to genetic engineering and other methods (e.g., supplemental UV application in greenhouses) to improve growth and nutritional quality of lettuce. However, the beneficial effect of AMF on the production and quality of this crop is highly dependent on several factors: type of lettuce, species of AMF and several factors related to cultural practices, such as the water regime applied to lettuce plants, the season chosen for cultivating lettuces and carbon dioxide $\left(\mathrm{CO}_{2}\right)$ supplementation within the greenhouse. Another important aspect that remains to be elucidated is the assessment of the potential biological effects that the enhanced amounts of nutraceuticals, vitamins and minerals accumulated in leaves of mycorrhizal lettuces could exert.

\section{Acknowledgments}

The authors wish to thank R. Esteban and J. I. García-Plazaola for analyses of carotenoids and tocopherols, A. Hernández (Atens, Tarragona, Spain) for providing mycorrhizal inoculum, J. M. García-Mina and J. Erro (International-R \& D Roullier Group Timac-Agro, Orcoyen, Navarra, Spain) for their contribution in the study focused on the influence of phosphorus sources on the effectiveness of mycorrhizal fungi for improving the nutritional quality of lettuce, as well as I. Pascual, M. Oyarzun and A. Urdiáin for technical support. M. Baslam was the recipient of a grant from Asociación de Amigos de la Universidad de Navarra (ADA).

\section{References and Note}

1. Edreva, A.; Velikova, V.; Tsonev, T.; Dagnon, S.; Gürel, A.; Aktaş, L.; Gesheva, E. Stress-protective role of secondary metabolites: Diversity of functions and mechanisms. Gen. Appl. Plant Physiol. 2008, 34, 67-78.

2. Bennett, R.N.; Wallsgrove, R.M. Secondary metabolites in plant defence mechanisms. New Phytol. 1994, 127, 617-633.

3. Simopoulos, A.P. Redefining dietary recommendations and food safety. World Rev. Nutr. Diet. 1998, 83, 219-222.

4. Calvo, M.M. Lutein: A valuable ingredient of fruit and vegetables. Crit. Rev. Food Sci. 2005, 45, 671-696.

5. Rao, A.V.; Rao, L.G. Carotenoids and human health. Pharmacol. Res. 2007, 55, 207-216.

6. You, Q.; Wang, B.; Chen, F.; Huang, Z.; Wang, X.; Luo, P.G. Comparison of anthocyanins and phenolics in organically and conventionally grown blueberries in selected cultivars. Food Chem. 2011, 125, 201-208.

7. Serafini, M.; Bugianesi, R.; Salucci, M.; Azzini, E.; Raguzzini, A.; Maiani, G. Effect of acute ingestion of fresh and stored lettuce (Lactuca sativa) on plasma total antioxidant capacity and antioxidant levels in human subjects. Br. J. Nutr. 2002, 88, 615-623.

8. Llorach, R.; Martínez-Sánchez, A.; Tomás-Barberán, F.A.; Gil, M.I.; Ferreres, F. Characterisation of polyphenols and antioxidant properties of five lettuce varieties and escarole. Food Chem. 2008, 108, 1028-1038. 
9. Nicolle, C.; Cardinault, N.; Gueux, E.; Jaffrelo, L.; Rock, E. Health effect of vegetable-based diet: Lettuce consumption improves cholesterol metabolism and antioxidant status in the rat. Clin. Nutr. 2004, 23, 605-614.

10. Borghi, S. Special: IV range (vegetables). Colt. Protette 2003, 32, 21-43.

11. Mou, B. Nutrient content of lettuce and its improvement. Curr. Nutr. Food Sci. 2009, 5, 242-248.

12. Kader, A.A. Fresh-Cut Produce: Tracks and Trends. In Fresh-Cut Fruits and Vegetables: Science, Technology, and Market; Lamikanra, O., Ed.; CRC Press: Boca Raton, FL, USA, 2002; pp. 21-30.

13. Jain, A.K.; Nessler, C.L. Metabolic engineering of an alternative pathway for ascorbic acid biosynthesis in plants. Mol. Breed. 2000, 6, 73-78.

14. Yabuta, Y.; Tanaka, H.; Yoshimura, S.; Suzuki, A.; Tamoi, M.; Maruta, T.; Shigeoka, S. Improvement of vitamin $\mathrm{E}$ quality and quantity in tobacco and lettuce by chloroplast genetic engineering. Transgenic Res. 2012, doi:10.1007/s11248-012-9656-5.

15. Goto, F.; Yoshihara, T.; Saiki, H. Iron accumulation and enhanced growth in transgenic lettuce plants expressing the iron-binding protein ferritin. Theor. Appl. Genet. 2000, 100, 658-664.

16. Smith, F.A.; Smith, S.E. What is the significance of the arbuscular mycorrhizal colonisation of many economically important crop plants? Plant Soil 2011, 348, 63-79.

17. Gianinazzi, S.; Gollote, A.; Binet, M.-N.; van Tuinen, D.; Redecker, D.; Wipf, D. Agroecology: The key role of arbuscular mycorrhizas in ecosystem services. Mycorrhiza 2010, 20, 519-530.

18. Hause, B.; Mrosk, C.; Isayenkov, S.; Strack, D. Jasmonates in arbuscular mycorrhizal interactions. Phytochemistry 2007, 68, 101-110.

19. Walter, M.H.; Floss, D.S.; Strack, D. Apocarotenoids: Hormones, mycorrhizal metabolites and aroma volatiles. Planta 2010, 232, 1-17.

20. Aroca, R.; Ruiz-Lozano, J.M.; Zamarreño, A.M.; Paz, J.A.; García-Mina, J.M.; Pozo, M.J.; López-Ráez, J.A. Arbuscular mycorrhizal symbiosis influences strigolactone production under salinity and alleviates salt stress in lettuce plants. J. Plant Physiol. 2013, 170, 47-55.

21. Garmendia, I.; Goicoechea, N.; Aguirreolea, J. Antioxidant metabolism in asymptomatic leaves of Verticillium-infected pepper associated with an arbuscular mycorrhizal fungus. J. Phytopathol. 2004, 152, 593-599.

22. Vosátka, M.; Látr, A.; Gianinazzi, S.; Albrechtová, J. Development of arbuscular mycorrhizal biotechnology and industry: Current achievements and bottlenecks. Symbiosis 2013, doi:10.1007/ s13199-012-0208-9.

23. Fitter, A.H.; Helgason, T.; Hodge, A. Nutritional exchanges in the arbuscular mycorrhizal symbiosis: Implications for sustainable agriculture. Fungal Biol. Rev. 2011, 25, 68-72.

24. Mulabagal, V.; Ngouajio, M.; Nair, A.; Zhang, Y.; Gottumukkala, A.L.; Nair, M.G. In vitro evaluation of red and green lettuce (Lactuca sativa) for functional food properties. Food Chem. 2010, 118, 300-306.

25. Afek, U.; Rinaldelli, E.; Menge, J.A.; Johnson, E.L.V.; Pond, E. Mycorrhizal species, root age, and position of mycorrhizal inoculum influence colonization of cotton, onion, and pepper Seedlings. J. Am. Soc. Hort. Sci. 1990, 115, 938-942. 
26. Borkowska, B. Growth and photosynthetic activity of micropropagated strawberry plants inoculated with endomycorrhizal fungi (AMF) and growing under drought stress. Acta. Physiol. Plant 2002, 24, 365-370.

27. Bolandnazar, S.A.; Neyshabouri, M.R.; Aliasgharzad, N.; Chaparzadeh, N. Effects of mycorrhizal colonization on growth parameters of onion under different irrigation and soil conditions. Pak. J. Biol. Sci. 2007, 10, 1491-1495.

28. Sohrabia, Y.; Heidaria, G.; Weisanya, W.; Ghasemi-Golezanib, K.; Mohammadic, K. Some physiological responses of chickpea cultivars to arbuscular mycorrhiza under drought stress. Russ. J. Plant Physl. 2012, 59, 708-716.

29. Wu, Q.S.; Zou, Y.N. Evaluating effectiveness of four inoculation methods with arbuscular mycorrhizal fungi on trifoliate orange seedlings. Int. J. Agric. Biol. 2012, 14, 266-270.

30. Selvaraj, T.; Nisha, M.C.; Rajeshkumar, S. Effect of indigenous arbuscular mycorrhizal fungi on some growth parameters and phytochemical constituents of Pogostemon patchouli Pellet. Maejo. Int. J. Sci. Technol. 2009, 3, 222-234.

31. Baslam, M.; Garmendia, I.; Goicoechea, N. Arbuscular mycorrhizal fungi (AMF) improved growth and nutritional quality of greenhouse grown lettuce. J. Agric. Food Chem. 2011, 59, 5504-5515.

32. Baslam, M.; Esteban, R.; García-Plazaola, J.I.; Goicoechea, N. Effectiveness of arbuscular mycorrhizal fungi (AMF) for inducing the accumulation of major carotenoids, chlorophylls and tocopherol in green and red leaf lettuces. Appl. Microbiol. Biotechnol. 2012, doi:10.1007/s00253012-4526-x.

33. Baslam, M.; Pascual, I.; Sánchez-Díaz, M.; Erro, J.; García-Mina, J.M.; Goicoechea, N. Improvement of nutritional quality of greenhouse-grown lettuce by arbuscular mycorrhizal fungi is conditioned by the source of phosphorus nutrition. J. Agric. Food Chem. 2011, 59, 11129-11140.

34. Baslam, M.; Goicoechea, N. Water deficit improved the capacity of arbuscular mycorrhizal fungi (AMF) for inducing the accumulation of antioxidant compounds in lettuce leaves. Mycorrhiza 2012, 22, 347-359.

35. Demming-Adams, B.; Adams, W.W., III. Chlorophyll and carotenoid composition in leaves of Euonymus kiautschovicus acclimated to different degrees of light stress in the field. Aust. J. Plant Physiol. 1996, 23, 649-659.

36. Cazzonelli, D.I. Carotenoids in nature: Insights from plants and beyond. Funct. Plant Biol. 2011, $38,833-847$.

37. Cazzonelli, C.I.; Pogson, B.J. Source to sink: Regulation of carotenoid biosynthesis in plants. Trends Plant Sci. 2010, 15, 266-274.

38. Sommer, A.; Davidson, F.R. Assessment and control of vitamin A deficiency: The Annecy Accords. J. Nutr. 2002, 132, 2845S-2850S.

39. Tapiero, H.; Townsend, D.M.; Tew, K.D. The role of carotenoids in the prevention of human pathologies. Biomed. Pharmacother. 2004, 58, 100-110.

40. Voutilainen, S.; Nurmi, T.; Mursu, J.; Rissanen, T. Carotenoids and cardiovascular health. Am. J. Clin. Nutr. 2006, 83, 1265-1271.

41. Paiva, S.A.R.; Russell, R.M. $\beta$-Carotene and other carotenoids as antioxidants. J. Am. Coll. Nutr. 1999, 18, 426-433. 
42. Strack, D.; Fester, T. Isoprenoid metabolism and plastid reorganization in arbuscular mycorrhizal roots. New Phytol. 2006, 172, 22-34.

43. Walter, M.H.; Floss, D.S.; Hans, J.; Fester, T.; Strack, D. Apocarotenoid biosynthesis in arbuscular mycorrhizal roots: Contributions from methylerythritol phosphate pathway isogenes and tools for its manipulation. Phytochemistry 2007, 68, 130-138.

44. Ulrichs, C.; Fischer, G.; Büttner, C.; Mewis, I. Comparison of lycopene, $\beta$-carotene and phenolic contents of tomato using conventional and ecological horticultural practices, and arbuscular mycorrhizal fungi (AMF). Agron. Colomb. 2008, 26, 40-46.

45. Mena-Violante, H.G.; Ocampo-Jiménez, O.; Dendooven, L.; Martínez-Soto, G.; González-Castañeda, J.; Davies, F.T., Jr.; Olalde-Portugal, V. Arbuscular mycorrhizal fungi enhance fruit growth and quality of chile ancho (Capsicum annuum L. cv San Luis) plants exposed to drought. Mycorrhiza 2006, 16, 261-267.

46. Giovannetti, M.; Avio, L.; Barale, R.; Ceccarelli, N.; Cristofani, R.; Lezzi, A.; Mignolli, F.; Picciarelli, P.; Pinto, B.; Reali, D.; et al. Nutraceutical value and safety of tomato fruits produced by mycorrhizal plants. Brit. J. Nutr. 2012, 107, 242-251.

47. Kainulainen, P.; Utriainen, J.; Holopainen, J.K.; Oksanen, J.; Holopainen, T. Influence of elevated ozone and limited nitrogen availability on conifer seedlings in an open-air fumigation system: Effects on growth, nutrient content, mycorrhiza, needle ultrastructure, starch and secondary compounds. Glob. Change Biol. 2000, 6, 335-344.

48. Valladares, F.; García Plazaola, J.I.; Morales, F.; Niinemets, U. Photosynthetic Responses to Radiation. In Terrestrial Photosynthesis in a Changing Environment. A Molecular, Physiological, and Ecological Approach; Flexas, J., Loreto, F., Medrano, H., Eds.; Cambridge University Press: Cambridge, UK, 2012; pp. 239-256.

49. Ma, L.; Lin, X.M. Effects of lutein and zeaxanthin on aspects of eye health. J. Sci. Food Agric. 2010, 90, 2-12.

50. Caldwell, C.R.; Britz, S.J. Effect of supplemental ultraviolet radiation on the carotenoid and chlorophyll composition of green house-grown leaf lettuce (Lactuca sativa L.) cultivars. J. Food Compos. Anal. 2006, 19, 637-644.

51. Baslam, M.; Garmendia, I.; Goicoechea, N. Elevated $\mathrm{CO}_{2}$ may impair the beneficial effect of arbuscular mycorrhizal fungi (AMF) on the mineral and phytochemical quality of lettuce. Ann. Appl. Biol. 2012, 161, 180-191.

52. Bravo, L. Polyphenols: Chemistry, dietary sources, metabolism, and nutritional significance. Nutr. Rev. 1998, 11, 317-333.

53. Lattanzio, V.; Lattanzio, V.M.T.; Cardinali, A. Role of Phenolics in the Resistance Mechanisms of Plants against Fungal Pathogens and Insects. In Phytochemistry: Advances in Research; Imperato, F., Ed.; Research Signpost: Kerala, India, 2006; pp. 23-67.

54. Cai, Y.; Luo, Q.; Sun, M.; Corke, H. Antioxidant activity and phenolic compounds of 112 traditional Chinese medicinal plants associated with anticancer. Life Sci. 2004, 74, 2157-2184.

55. Fu, L.; Xu, B.T.; Xu, X.R.; Gan, R.Y.; Zhang, Y.; Xia, E.Q.; Li, H.B. Antioxidant capacities and total phenolic contents of 62 fruits. Food Chem. 2011, 129, 345-350.

56. Francisco, A.; Tomás-Barberán, F.A.; Juan, C.E. Phenolic compounds and related enzymes as determinants of quality in fruits and vegetables. J. Sci. Food Agric. 2001, 81, 853-876. 
57. Ganz, T.R.; Kailis, S.G.; Abbott, L.K. Mycorrhizal colonization and its effect on growth phosphorus uptake and tissue phenolic content in the European olive (Olea europaea L.). Adv. Hortic. Sci. 2002, 16, 109-116.

58. Toussaint, J.P.; Smith, F.A.; Smith, S.E. Arbuscular mycorrhizal fungi can induce the production of phytochemicals in sweet basil irrespective of phosphorus nutrition. Mycorrhiza 2007, 17, 291-297.

59. Lee, J.M.; Scagel, C.F. Chicoric acid found in basil (Ocimum basilicum L.) leaves. Food Chem. 2009, 115, 650-656.

60. Castellanos-Morales, V.; Villegas, J.; Wendelin, S.; Vierheilig, H.; Eder, R.; Cárdenas-Navarro, R. Root colonisation by the arbuscular mycorrhizal fungus Glomus intraradices alters the quality of strawberry fruits (Fragaria ananassa Duch.) at different nitrogen levels. J. Sci. Food Agric. 2010, 90, 1774-1782.

61. Cavagnaro, T.R.; Gleadow, R.M.; Miller, R.E. Plant nutrient acquisition and utilization in a high carbon dioxide world. Funct. Plant Biol. 2011, 38, 87-96.

62. Mandal, S.M.; Chakraborty, D.; Dey, S. Phenolic acids act as signaling molecules in plant-microbe symbioses. Plant Signal. Behav. 2010, 5, 359-368.

63. Janagath, I.B.; Crozier, A. Dietary Flavonoids and Phenolic Compounds. In Plant Phenolics and Human Health. Biochemistry, Nutrition, and Pharmacology; Fraga, C.G., Ed.; Wiley \& Sons, Inc.: Hoboken, NJ, USA, 2010; pp. 1-50.

64. Chalker-Scott, L. Environmental significance of anthocyanins in plant stress responses. Photochem. Photobiol. 1999, 70, 1-9.

65. Stintzing, F.C.; Carle, R. Functional properties of anthocyanins and betalains in plants, food, and in human nutrition. Trends Food Sci. Technol. 2004, 15, 19-38.

66. Ross, J.A.; Kasum, C.M. Dietary flavonoids: Bioavailability, metabolic effects, and safety. Annu. Rev. Nutr. 2002, 22, 19-34.

67. Poulton, J.L.; Koide, R.T.; Stephenson, A.G. Effects of mycorrhizal infection and soil phosphorus availability on in vitro and in vivo pollen performance in Lycopersicon esculentum (Solanaceae). Am. J. Bot. 2001, 88, 1786-1793.

68. Smirnoff, N.; Wheeler, G.L. Ascorbic acid in plants: Biosynthesis and function. CRC Crit. Rev. Biochem. Mol. Biol. 2000, 35, 291-314.

69. Arrigoni, O.; de Tullio, M.C. The role of ascorbic acid in cell metabolism: Between gene-directed functions and unpredictable chemical reactions. J. Plant Physiol. 2000, 157, 481-488.

70. Smirnoff, N. Ascorbate biosynthesis and function in photoprotection. Philos. Trans. R. Soc. Lond. B Biol. Sci. 2000, 355, 1455-1464.

71. Davey, M.W.; van Montagu, M.; Inzé, D.; Sanmartin, M.; Kanellis, A.; Smirnoff, N.; Benzie, I.J.J.; Strain, J.J.; Favell, D.; Fletcher, J. Plant L-ascorbic acid: Chemistry, function, metabolism, bioavailability and effects of processing. J. Sci. Food Agric. 2000, 80, 825-860.

72. Lee, S.K.; Kader, A.A. Preharvest and postharvest factors influencing vitamin $\mathrm{C}$ content of horticultural crops. Postharvest Biol. Technol. 2000, 20, 207-220.

73. Marshall, J.R. Prevention of colorectal cancer: Diet, chemoprevention and lifestyle. Gastroenterol. Clin. N 2008, 37, 73-82. 
74. Davidson, P.G.; Touger-Decker, R. Chemopreventive role of fruits and vegetables in oropharyngeal cancer. Nutr. Clin. Pract. 2009, 24, 250-260.

75. Qiang-Sheng, W.; Ren-Xue, X.; Ying-Ning, Z. Reactive oxygen metabolism in mycorrhizal and non-mycorrhizal citrus (Poncirus trifoliata) seedlings subjected to water stress. J. Plant Physiol. 2006, 163, 1101-1110.

76. Oh, M.-M.; Trick, H.N.; Rajashekar, C.B. Secondary metabolism and antioxidants are involved in environmental adaptation and stress tolerance in lettuce. J. Plant Physiol. 2009, 166, 180-191.

77. Potters, G.; Horemans, N.; Jansen, M.A.K. The cellular redox state in plant stress biology-A charging concept. Plant Physiol. Bioch. 2010, 48, 292-300.

78. Kohler, J.; Hernández, J.A.; Caravaca, F.; Roldán, A. Induction of antioxidant enzymes is involved in the greater effectiveness of a PGPR versus AM fungi with respect to increasing the tolerance of lettuce to severe salt stress. Environ. Exp. Bot. 2009, 65, 245-252.

79. Falk, J.; Munné-Bosch, S. Tocochromanol functions in plants: Antioxidation and beyond. J. Exp. Bot. 2010, 61, 1549-1566.

80. Bramley, P.M.; Elmadfa, I.; Kafatos, A.; Kelly, F.J.; Manios, Y.; Roxborough, H.E.; Schuch, W.; Sheehy, P.J.A.; Wagner, K.H. Review: Vitamin E. J. Sci. Food Agric. 2000, 80, 913-938.

81. Clarke, M.W.; Burnett, J.R.; Croft, K.D. Vitamin E in human health and disease. Crit. Rev. Clin. Lab. Sci. 2008, 45, 417-450.

82. Lira, F.S.; Rosa, J.C.; Cunha, C.A.; Ribeiro, E.B.; Oller do Nascimento, C.; Oyama, L.M.; Mota, J.F. Supplementing alpha-tocopherol (vitamin E) and vitamin D3 in high fat diet decrease IL-6 production in murine epididymal adipose tissue and 3T3-L1 adipocytes following LPS stimulation. Lipids Health Dis. 2011, 10, 37.

83. Lizarazo, K.; Fernández-Marín, B.; Becerril, J.M.; García-Plazaola, J.I. Ageing and irradiance enhance vitamin E content in green edible tissues from crop plants. J. Sci. Food Agric. 2010, 90, 1994-1999.

84. Garmendia, I.; Goicoechea, N.; Aguirreolea, J. Effectiveness of three Glomus species in protecting pepper (Capsicum annuum L.) against verticillium wilt. Biol. Control 2004, 31, 296-305.

85. Martínez-Ballesta, M.C.; Dominguez-Perles, R.; Moreno, D.A.; Muries, B.; Alcaraz-López, C.; Bastías, E.; García-Viguera, C.; Carvajal, M. Minerals in plant food: Effect of agricultural practices and role in human health. Agron. Sustain. Dev. 2010, 30, 295-309.

86. Welch, R.M.; Graham, R.D. Breeding for micronutrients in staple food crops from a human nutrition perspective. J. Exp. Bot. 2004, 55, 353-364.

87. Graham, R.D.; Welch, R.M.; Bouis, H.E. Addressing micronutrient malnutrition through enhancing the nutritional quality of staple foods: Principles, perspectives and knowledge gaps. Adv. Agronom. 2001, 70, 77-142.

88. ACC/SCN (Administrative Committee on Coordination, Subcommitee on Nutrition); International Food Policy Research Institute. Fourth Report on the World Nutrition Situation: United Nations, 2000.

89. Brown, K.H.; Wuehler, S.E. Zinc and Human Health: The Results of Recent Trials and Implications for Programmed Interventions and Research; The Micronutrient Initiative/International Development Research Centre: Ottawa, Canada, 2000. 
90. Copper Development Association. Copper in Human Health. Available online: http://www. copperinfo.co.uk/health/ (accessed on 5 November 2012).

91. Clark, R.B.; Zeto, S.K. Mineral acquisition by arbuscular mycorrhizal plants. J. Plant Nutr. 2000, 23, 867-902.

92. Kothari, S.K.; Marschner, H.; Römheld, V. Contribution of VA mycorrhizal hyphae in acquisition of phosphorus and zinc by maize grown in a calcareous soil. Plant Soil 1991, 131, 177-185.

93. Li, X.L.; Marschner, H.; George, E. Acquisition of phosphorus and copper by VA-mycorrhizal hyphae and root-to-shoot transport in white clover. Plant Soil 1991, 136, 49-57.

94. Azcón, R.; Ambrosano, E.; Charest, C. Nutrient acquisition in mycorrhizal lettuce plants under different phosphorus and nitrogen concentration. Plant Sci. 2003, 165, 1137-1145.

95. Goicoechea, N.; Antolín, M.C.; Sánchez-Díaz, M. Influence of arbuscular mycorrhizae and Rhizobium on nutrient content and water relations in drought stressed alfalfa. Plant Soil 1997, 192, 261-268.

96. Augé, R.M. Water relations, drought and vesicular-arbuscular mycorrhizal symbiosis. Mycorrhiza 2001, 11, 3-42.

97. Zuccarini, P. Mycorrhizal infection ameliorates chlorophyll content and nutrient uptake of lettuce exposed to saline irrigation. Plant Soil Environ. 2007, 53, 283-289.

98. Loladze, I. Rising atmospheric $\mathrm{CO}_{2}$ and human nutrition: toward globally imbalanced plant stoichiometry? Trends Ecol. Evol. 2002, 17, 457-461.

99. Jifon, J.L.; Graham, J.H.; Drouillard, D.L.; Syvertsen, J.P. Growth depression of mycorrhizal Citrus seedlings grown at high phosphorus supply is mitigated by elevated $\mathrm{CO}_{2}$. New Phytol. 2002, 153, 133-142.

100. Treseder, K.K.; Allen, M.F. Mycorrhizal fungi have a potential role in soil carbon storage under elevated $\mathrm{CO}_{2}$ and nitrogen deposition. New Phytol. 2000, 147, 189-200.

(C) 2013 by the authors; licensee MDPI, Basel, Switzerland. This article is an open access article distributed under the terms and conditions of the Creative Commons Attribution license (http://creativecommons.org/licenses/by/3.0/). 